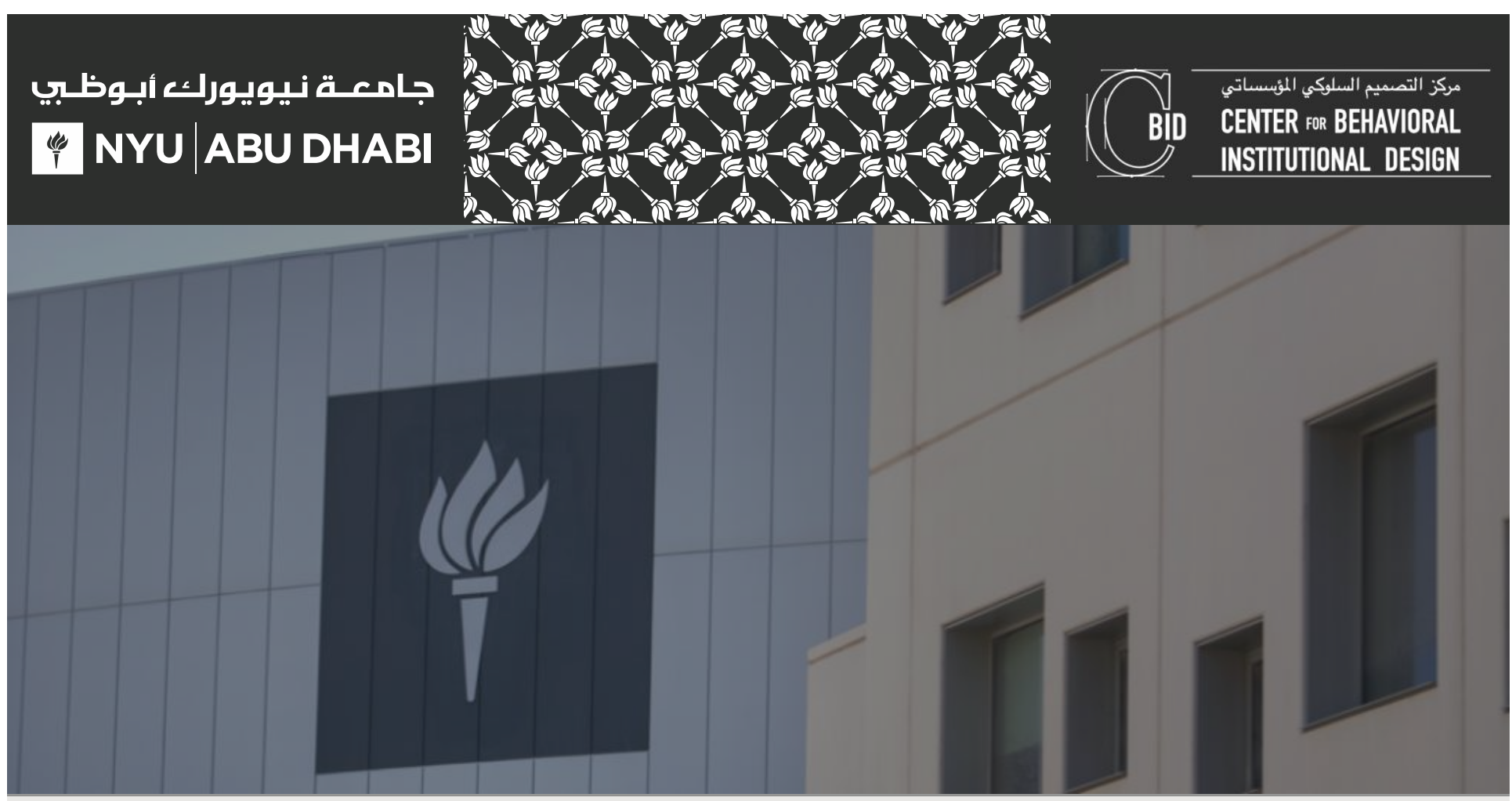

\title{
The Effect of Group Identity on Hiring Decisions with Incomplete Information
}

\author{
Fortuna Casoria, Ernesto Reuben, and \\ Christina Rott
}

Working Paper \# 0059

November 2020 


\title{
The effect of group identity on hiring decisions with incomplete information
}

\author{
Fortuna Casoria \\ Université de Lyon, Centre National de la Recherche Scientifique, Groupe \\ d'Analyse et de Théorie Economique, e-mail: casoria@gate.cnrs.fr \\ Ernesto Reuben \\ New York University Abu Dhabi, Center for Behavioral Institutional Design, \\ Luxembourg Institute of Socio-Economic Research, e-mail: ereuben@nyu.edu \\ Christina Rott \\ Department of Management and Organization, School of Business and \\ Economics, Vrije Universiteit Amsterdam, e-mail: c.e.rott@vu.nl
}

\begin{abstract}
We investigate the effects of group identity on hiring decisions with adverse selection problems. We run a laboratory experiment in which employers cannot observe a worker's ability nor verify the veracity of the ability the worker claims to have. We evaluate whether sharing an identity results in employers discriminating in favor of ingroup workers, and whether it helps workers and employers overcome the adverse selection problem. We induce identities using the minimal group paradigm and study two settings: one where workers cannot change their identity and one where they can. Although sharing a common identity does not make the worker's claims more honest, employers strongly discriminate in favor of ingroup workers when identities are fixed. Discrimination cannot be explained by employers' beliefs and hence seems to be taste-based. When possible, few workers change their identity. However, the mere possibility of changing identities erodes the employers' trust towards ingroup workers and eliminates discrimination.
\end{abstract}

This version: November 2020

Note: We thank participants of the BeeLab meeting at Maastricht University, and participants of several seminars and conferences for their comments and suggestions. This research has been performed in the framework of the LABEX CORTEX (ANR-11-LABX-0042) of Université de Lyon, within the program Investissements d'Avenir (ANR-11-IDEX-007) operated by the Agence Nationale de la Recherche (ANR). The authors gratefully acknowledge financial support from the Graduate School of Business and Economics, Maastricht University. 


\section{Introduction}

A large stream of research has provided consistent evidence of discrimination in hiring decisions. ${ }^{1}$ Recently, scholars have shown that employers tend to favor candidates that are similar to themselves in terms of tastes, leisure pursuits, and experiences (e.g., Rivera, 2012). Among other explanations, these findings are consistent with ingroup favoritism - the tendency displayed by individuals to treat members of the own identity group more favorably than those from different identities. While ingroup favoritism is commonly associated with unfavorable consequences, it could also help organizations overcome problems arising from individuals' selfinterest. After all, many studies show that sharing a common identity increases cooperation (e.g., Eckel and Grossman, 2005), coordination (e.g., Chen and Chen, 2011), and trust (e.g., Falk and Zehnder, 2013). ${ }^{2}$ The hiring process is of interest because employers often do not know the candidates' abilities before hiring them and evidence provided by the candidates is typically unverifiable. In this situation, if there is a large share of low-ability candidates, it can be suboptimal for employers to hire at all. This study aims to investigate the role of ingroup favoritism in overcoming adverse selection problems in hiring decisions and identify whether ingroup favoritism results in taste-based or statistical discrimination.

We run a laboratory experiment using an adverse selection hiring game (Charness and Dufwenberg, 2011). In the game, an employer decides whether to hire a worker or not. The worker can be of low or high ability, but his ability is private information, hence unknown to the employer. Before the hiring decision, the worker sends a message to the employer in which he can claim to be of either ability. The prediction with the standard assumption of own-payoff maximization is for the worker to send the high-ability message and for the employer not to hire. However, as Charness and Dufwenberg (2011) show, the adverse selection problem is alleviated if a substantial fraction of workers is unwilling to lie about their ability, making it profitable for the employer to hire.

We introduce minimal group identities before participants play the game (Tajfel, 1970). Thereafter, we randomly assign participants to roles (employer or worker), workers to abilities (high or low), and employers are matched with either an ingroup or an outgroup worker. We ensured that participants know that abilities are randomly assigned, which rules out an asso-

\footnotetext{
${ }^{1} \mathrm{~A}$ lot of the literature studies discrimination against racial and ethnic minorities as well as women in the likelihood of being interviewed or hired. In addition, individuals with lower social status, proxied by their names or region, have been found to experience discrimination in many (high-status) professions (e.g., Riach and Rich, 2002; Bertrand and Mullainathan, 2004; Oreopoulos, 2011; Edo et al., 2019). Recent research has even shown that common accents are more hirable, while regional accents are discriminated against (Rakić et al., 2011).

${ }^{2}$ We concentrate on situations where identities are observable. Therefore, we do not distinguish between ingroup favoritism and outgroup discrimination.
} 
ciation between ability and group identity by design. Based on insights from the literature, we conjecture that group identities can affect hiring outcomes. First, workers might lie less to ingroup than to outgroup employers. Second, employers might discriminate in favor of ingroup workers because they expect ingroup workers to be more truthful (statistical discrimination) or because they exhibit altruism towards ingroup members (taste-based discrimination). We elicit the employer's expectations about the workers' truthfulness to distinguish between these two forms of discrimination.

Empirical and anecdotal evidence shows that workers respond to discrimination by adapting aspects of their identity. For instance, job seekers might change their name, disguise their accent, or opt for gender-free applications (Arai and Thoursie, 2009; Biavaschi et al., 2017). ${ }^{3}$ In fact, Akerlof and Kranton (2000) argue that the choice of one's identity may be one of the most important economic decisions people make. ${ }^{4}$ Inspired by these papers, we implement two treatments: a treatment with fixed identities and a treatment with flexible identities where workers can choose whether to keep their initial identity or adopt the employer's identity. We investigate not only whether workers change their identity but also how the option to change identity affects the lying and hiring decisions of ingroup and outgroup employer-worker pairs.

We find that identity does not affect lying since workers lie equally often to ingroup and outgroup employers. However, employers exhibit ingroup favoritism by hiring ingroup workers significantly more often than outgroup workers. Interestingly, employers do not trust messages from ingroup workers more than those of outgroup workers. In other words, discrimination in favor of ingroup workers does not emerge due to statistical discrimination, suggesting that it is driven by tastes. With flexible identities, we find that few workers change their identity. Nevertheless, the possibility of changing identity eliminates discrimination in favor of ingroup workers but also reduces overall hiring rates.

\section{The experiment}

\subsection{Adverse selection hiring game}

We implement a variation of the game used by Charness and Dufwenberg (2011). In the game, an employer is matched with a worker, who can be of low or high ability. The employer knows that the probability of being matched with a high-ability worker is $\frac{1}{2}$, but only the worker knows their realized ability. After learning their ability, the worker sends a preformulated cheap-talk

\footnotetext{
${ }^{3}$ In these studies, identity and individual traits are potentially correlated. An advantage of our experiment is that we can rule out an association between identity and a worker's ability.

${ }^{4}$ Other research considers identity choice in the context of multidimensional identities. Shayo (2009) analyzes how identification affects support for redistribution. Bernard et al. (2016) study the role of identity choice in shaping social structures.
} 


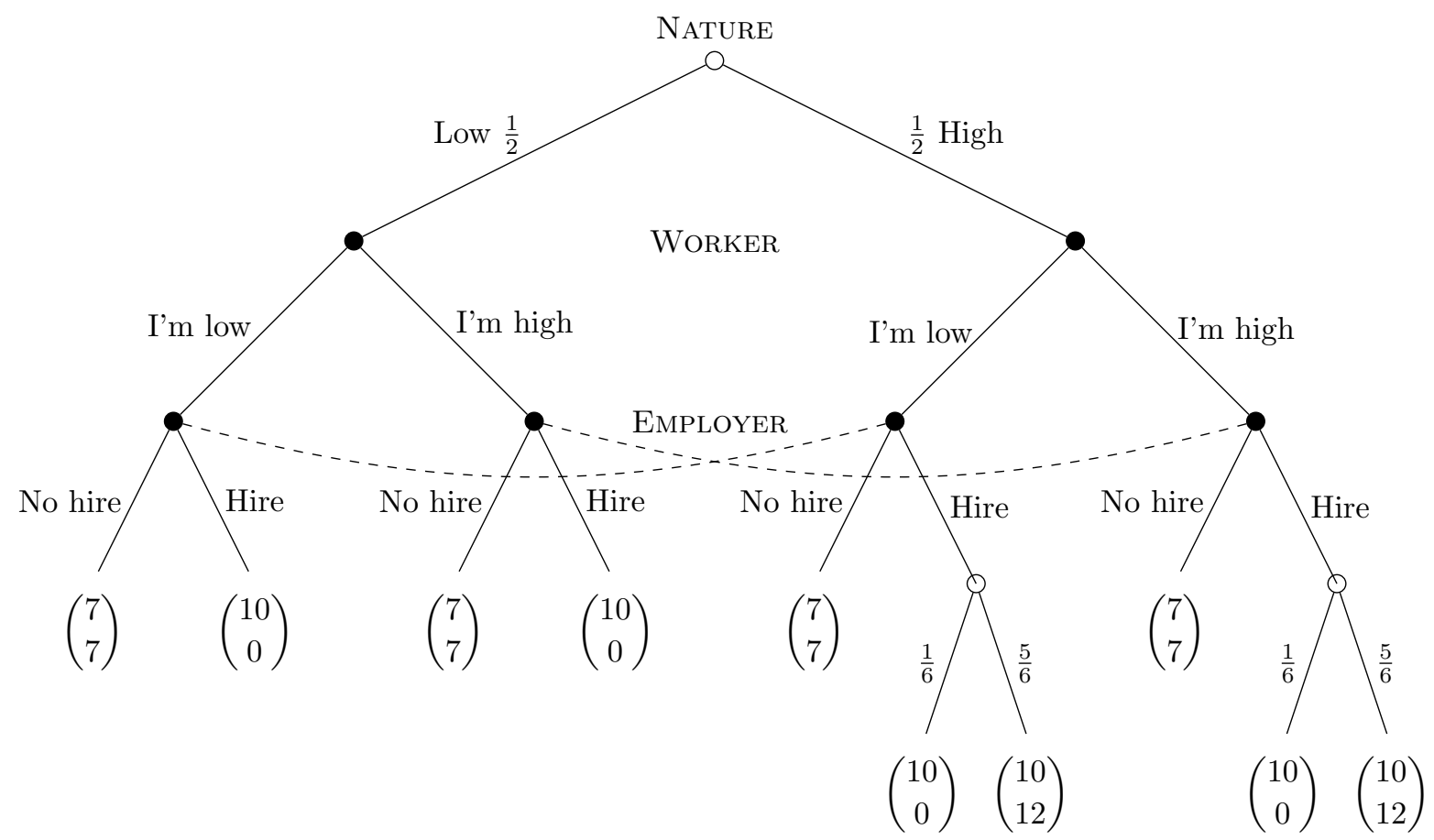

Figure 1. Game tree of the adverse selection hiring game

message to the employer. Workers choose between the message "I am in the low-ability group" and "I am in the high-ability group". After receiving the message, the employer decides whether to hire the worker or not. The game tree is depicted in Figure 1. If the employer does not hire, then the employer and the worker get $€ 7$ irrespective of the worker's ability. If the employer does hire, then the worker gets $€ 10$, and the employer's earnings depend on the worker's ability. If the worker is low ability, the employer gets $€ 0$. If the worker is high ability, the employer receives $€ 12$ with probability $\frac{5}{6}$ and $€ 0$ otherwise. As in Charness and Dufwenberg (2011), this feature guarantees that false messages by low-ability workers are contractually nonverifiable. ${ }^{5}$

\section{$2.2 \quad$ Experimental design}

The experiment consists of two parts. Participants are informed that they will receive the corresponding instructions at the beginning of each part.

\footnotetext{
${ }^{5}$ Like in Charness and Dufwenberg (2011), there is a final decision, not depicted in Figure 1, where the worker chooses between 'Accept' and 'Reject' after learning the employer's decision. Figure 1 shows the payoffs if the worker accepts. Rejecting is a dominated action since it gives both players a payoff of $€ 5$. Not surprisingly, 97.5\% (117 out of 120) of the workers accept. Since this decision does not affect the theoretical predictions or results, we omit it from our analysis. This decision is interesting in Charness and Dufwenberg (2011) because it is relevant in their other treatments. In our case, it is not, but we decided to keep it for our results to be comparable to theirs.
} 


\section{Part 1: Group identity}

In part 1, we induce group identity using the minimal group paradigm (Tajfel, 1970). As in many studies, we use the participants' revealed preferences to induce identities. ${ }^{6}$ We ask the participants to choose one of two smartphones: an iPhone 6 or a Samsung S6 Edge. Both smartphones have similar functionality, features, and price (around $€ 750$ when the study was conducted). To incentivize their decision, we conduct a lottery with a 1 in 750 chance of winning the chosen smartphone. ${ }^{7}$

\section{Part 2: Adverse selection hiring game and belief elicitation}

Part 2 consists of two stages. One stage is randomly drawn at the end of the session to determine everyone's payment. In the first stage, participants learn their role (employer or worker), observe each other's identity, and play the one-shot adverse selection hiring game described above. In the second stage, we elicit beliefs. Specifically, immediately after the hiring decision, we ask employers to indicate the probability that they are matched with a low-ability worker. The belief elicitation is incentivized using the mechanism proposed by Karni (2009). ${ }^{8}$

\section{Treatments}

We run two treatments. In treatment Fixed, the identity chosen in part 1 cannot be changed. In treatment Flexible, workers can revise their identity choice after observing their employer's identity but before sending their message. Employers know that workers can change identity, but they do not know whether the worker's identity they observe is the initially-chosen identity or not.

\subsection{Conjectures}

If all players are rational own-payoff maximizers, the adverse selection hiring game is easily solved. Intuitively, if the employer conditions her hiring on the worker's message, both highability and low-ability workers have an incentive to always send the message that results in a higher probability of being hired. However, if workers always send the same message, then messages are uninformative of the worker's ability, and the employer's expected earnings from

\footnotetext{
${ }^{6} \mathrm{~A}$ commonly-used approach is to ask participants for their preference over paintings by Klee and Kandinsky and then assign them to groups according to their stated tastes (e.g., Chen and Li, 2009; Gioia, 2017; Kranton and Sanders, 2017). Others have used preferences over movie genres (Dickinson et al., 2018), colors (Charness et al., 2007), and poetry (Kranton and Sanders, 2017).

${ }^{7}$ Participants know that their choice is anonymous and will be used in the second part of the experiment. They also indicate the strength of their preference for the chosen smartphone.

${ }^{8}$ We also ask workers to predict their employer's expectation of being matched with a low-ability worker.
} 
not hiring (i.e., $€ 7$ ) exceeds her payoff from hiring (i.e., $\frac{1}{2} \times \frac{5}{6} \times € 12=€ 5$ ). Hence, in equilibrium, employers do not condition their hiring on the message and never hire, making workers indifferent to what message to send.

Next, we consider how these predictions change if we assume some workers are unwilling to lie. Our goal is to provide a straightforward benchmark describing the conditions under which employers have an incentive to hire. For simplicity, we describe the case where players are risk-neutral, but the general intuition applies to other risk preferences. Over the past decades, substantial evidence has accumulated that some individuals have a preference for truthtelling (e.g., see Abeler et al., 2019). Here, we simply assume that a fraction $\theta$ of low-ability workers maximize their monetary earnings while the remaining $(1-\theta)$ are truthful and send the lowability message. Under this assumption, if we denote the employer's updated belief of being matched with a high-ability worker as $b_{H}$, then she prefers to hire as long as her payoff from hiring $\left(b_{H} \times \frac{5}{6} \times € 12\right)$ exceeds that from not hiring (i.e., $\left.€ 7\right)$. In other words, employers hire if their updated belief is above the threshold $b_{H}^{*}=\frac{7}{10}$. If employers hire workers who send a highability message, then earnings-maximizing high-ability and low-ability workers have a dominant strategy to send the high-ability message. Consequently, since the initial probability of a highability worker is $\frac{1}{2}$, the probability that a worker is high-ability conditional on observing a high-ability message boils down to $\frac{1}{1+\theta}$. Combining this with $b_{H}^{*}$ gives us the threshold fraction of low-ability workers who lie below which employers are willing to hire: $\theta^{*}=\frac{3}{7}$.

\section{The role of identity}

Here, we discuss the role of group identity, starting with the case where identities are fixed. There is considerable evidence that people favor ingroup over outgroup members in numerous domains; from simple allocation decisions to cooperation and trust games (e.g., see Eckel and Grossman, 2005; Chen and Li, 2009; Chen and Chen, 2011; Falk and Zehnder, 2013). A few studies report that ingroup favoritism applies to lying behavior. Rong et al. (2016) find that a shared identity decreases lying in guessing games preceded by a communication stage. Using natural identities, Maximiano and Chakravarty (2016) find that senders in a sender-receiver game lie less to ingroup (i.e., friends) than to outgroup receivers (i.e., strangers). In a repeated lemons market game, Butler (2014) finds less lying in ingroup matches. ${ }^{9}$ Given this evidence, we propose the following conjecture.

Conjecture 1 Fewer workers will lie to ingroup than to outgroup employers.

One reason for workers to lie less to ingroup employers is altruism towards ingroup members

\footnotetext{
${ }^{9}$ Not all studies find evidence of ingroup favoritism in lying. Feldhaus and Mans (2014) find no effect of social identity on lying in a sender-receiver game, while Benistant and Villeval (2019) find the same result in a Tullock contest with communication.
} 
(Chen and $\mathrm{Li}, 2009$ ). In this case, workers will lie less to ingroup employers to increase their earnings. Alternatively, it is plausible that it is psychologically costlier to lie to an ingroup than to an outgroup member. After all, lying is often seen as immoral and moral decisions depend on the closeness between the decision-maker and the potential victim (Bénabou et al., 2020). Although these are distinct reasons, in the simple model above, they boil down to a lower fraction of workers lying in ingroup than in outgroup pairs. ${ }^{10}$

Like workers, there are two straightforward reasons for employers to discriminate in favor of ingroup workers. The first reason is discrimination based on taste - i.e., altruism towards ingroup members. Employers increase workers' earnings by hiring them. Hence, altruism towards ingroup members can lead to a higher likelihood of hiring an ingroup worker if the employers' belief $b_{H}$ is not too extreme. ${ }^{11}$ The second reason is statistical discrimination. In other words, employers favoring ingroup workers because they believe they are less likely to lie (anticipating Conjecture 1), which is consistent with the evidence showing that individuals expect others to lie less to ingroup members (Benistant and Villeval, 2019). These arguments give us a second conjecture.

Conjecture 2 Employers are more likely to hire an ingroup than an outgroup worker.

Given that we elicit the employers' beliefs, we can further disentangle empirically taste-based and statistical discrimination. We formulate this as a third conjecture.

Conjecture 3 If employers discriminate statistically, their belief of being matched with a highability worker after a high-ability message will be higher for ingroup than for outgroup workers.

To conclude, we discuss the Flexible treatment. In this treatment, workers can switch their initial identity before it is revealed to employers. Since research on changing minimal identities is rare, ${ }^{12}$ it is unclear whether individuals will use initial or final identities to treat others as

\footnotetext{
${ }^{10}$ One could differentiate between these two reasons with the workers' expectations of each message's impact on the hiring decision. Altruism towards the ingroup predicts a positive association between the relative impact of sending the high-ability message and the likelihood of sending the truthful message. Since incentivized belief elicitation of counterfactual actions is inordinately complicated, we refrained from measuring these beliefs.

${ }^{11}$ If we define the utility of an employer as $u=\pi+\alpha$, where $\pi$ is the employer's pecuniary payoff, and $\alpha$ is the utility of increasing the worker's earnings by $€ 2$, then the employer hires if her updated belief is above $b_{H}^{*}=\frac{7-\alpha}{10}$. If altruism is higher towards ingroup than outgroup members (i.e., $\alpha^{I}>\alpha^{O}$ ), then there is discrimination in favor of the ingroup for beliefs $b_{H} \in\left(\frac{7-\alpha^{I}}{10}, \frac{7-\alpha^{O}}{10}\right)$.

${ }^{12} \mathrm{~A}$ few researchers have explored settings where individuals can change their affiliation to identity groups. Hargreaves Heap and Zizzo (2009) allow participants to trade group affiliations to play trust games. In Charness and Shmidov (2014), participants playing a public goods game can exit, exclude, and add others to their identity group. Hett et al. (2017) measure group identification preferences and their effect on distributional choices. Robin et al. (2014) find that participants strategically change their opinion to match those of principals, who, in turn, reward like-minded people.
} 
an ingroup or an outgroup member. If final identities are used, and there is ingroup favoritism (Conjectures 1 through 3 ), then workers have a strong incentive to match the identity of the employer, resulting in overall less lying and more hiring. If initial identities are used, then employers would like to hire workers with whom they share an initial identity, but they cannot tell by observing the final identity whether their initial identities match. This introduces a second adverse-selection problem, which could result in the breakdown of the effect of group identity on hiring. Hence, the effect of flexible identities is ambiguous. Finally, research on natural identities shows that switching one's identity is psychologically costly (Burke, 2006; Chandra, 2006). We use minimal group identities, but even a small psychological cost might be enough to deter workers from switching in the experiment.

\subsection{Procedures}

We conducted the experiment at BEElab in Maastricht University in the fall of 2015. Participants were undergraduate students. We ran ten sessions (five per treatment) with a total of 240 participants (120 per treatment). Each session took one hour, and participants earned, on average, $€ 12$, including a $€ 5$ show-up fee. Instructions were written with neutral language. The appendix contains samples of the instructions and screenshots.

\section{Results}

We collected 60 independent observations (i.e., employer-worker pairs) per treatment. In Fixed, we have 35 outgroup and 25 ingroup pairs, while in Flexible, we have 28 outgroup and 32 ingroup pairs. Throughout the analysis, we use the worker's initial identity in Flexible to determine whether workers and employers form an ingroup or an outgroup pair. Since only $10.0 \%$ of workers change their identity ( 6 out of 60 ), our results are not qualitatively different if we use the workers' assumed identity. ${ }^{13}$

\subsection{Workers' lying behavior}

As expected, low-ability workers lie significantly more often than high-ability workers. Across both treatments, $46.7 \%$ of low-ability workers lie (28 out of 60 ), while only $1.7 \%$ of high-ability workers do so ( 1 out of $60 ; \chi^{2}$ test, $p<0.001$ ). Henceforth, we focus on the behavior of low-ability workers.

\footnotetext{
${ }^{13}$ Since few workers change identity, we cannot draw reliable conclusions for this decision. Intriguingly, workers in ingroup and outgroup pairs change their identity similarly often ( 3 out of 28 vs. 3 out of $32 ; \chi^{2}$ test $p=0.863$ ). Moreover, the strength of preferences for the chosen smartphone is similar for workers who change identity and those who do not (Mann-Whitney $\mathrm{U}$ test, $p=0.684$ ).
} 


Fixed Flexible

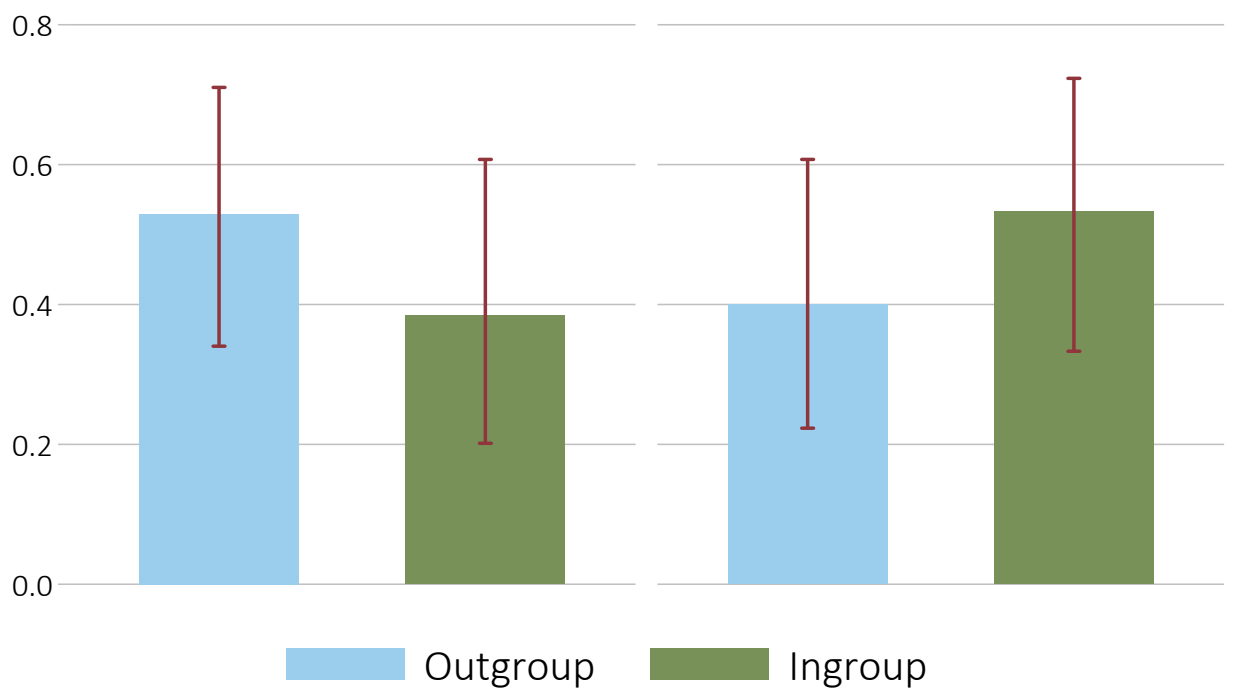

Figure 2. Fraction of low-ability workers who lie to the employer in Fixed and Flexible

Note: Error bars depict $90 \%$ confidence intervals. Ingroup and outgroup pairs are determined by the workers' initial identity.

Figure 2 depicts how frequently low-ability workers lie. In Fixed, $38.5 \%$ of low-ability workers lie in ingroup pairs ( 5 out of 13), which is slightly less often than the $52.9 \%$ who lie in outgroup pairs (9 out of 17). In Flexible, it is the other way around: $53.5 \%$ of low-ability workers lie in ingroup pairs ( 8 out of 15 ), and $40.0 \%$ lie in outgroup pairs (6 out of 15). These differences are not statistically significant ( $\chi^{2}$ tests, $p=0.431$ in Fixed and $p=0.464$ in Flexible). Note that these fractions are close to the threshold below which employers are willing to hire $\left(\theta^{*} \approx 42.9 \%\right)$. We also do not find evidence that being in the Fixed or Flexible treatment affects lying $\left(\chi^{2}\right.$ tests, $p=0.464$ for outgroup pairs and $p=0.431$ for ingroup pairs). Overall, we do not find support for Conjecture 1.

Result 1 With both fixed and flexible identities, low-ability workers lie similarly irrespective of whether the employer is an ingroup or an outgroup.

\subsection{Employers' beliefs and hiring behavior}

A substantial number of employers hire the worker, and their decision is highly dependent on the worker's message. Overall, $60.9 \%$ of the employers who received the high-ability message hire the worker (53 out of 87 ), while only $3.0 \%$ of the employers who received the low-ability message do ( 1 out of $33 ; \chi^{2}$ test, $p<0.001$ ). Thus, from here on, we focus on the hiring decisions and beliefs of employers who receive the high-ability message.

In Fixed, $74.4 \%$ of the employers hire the worker after receiving the high-ability message (32 


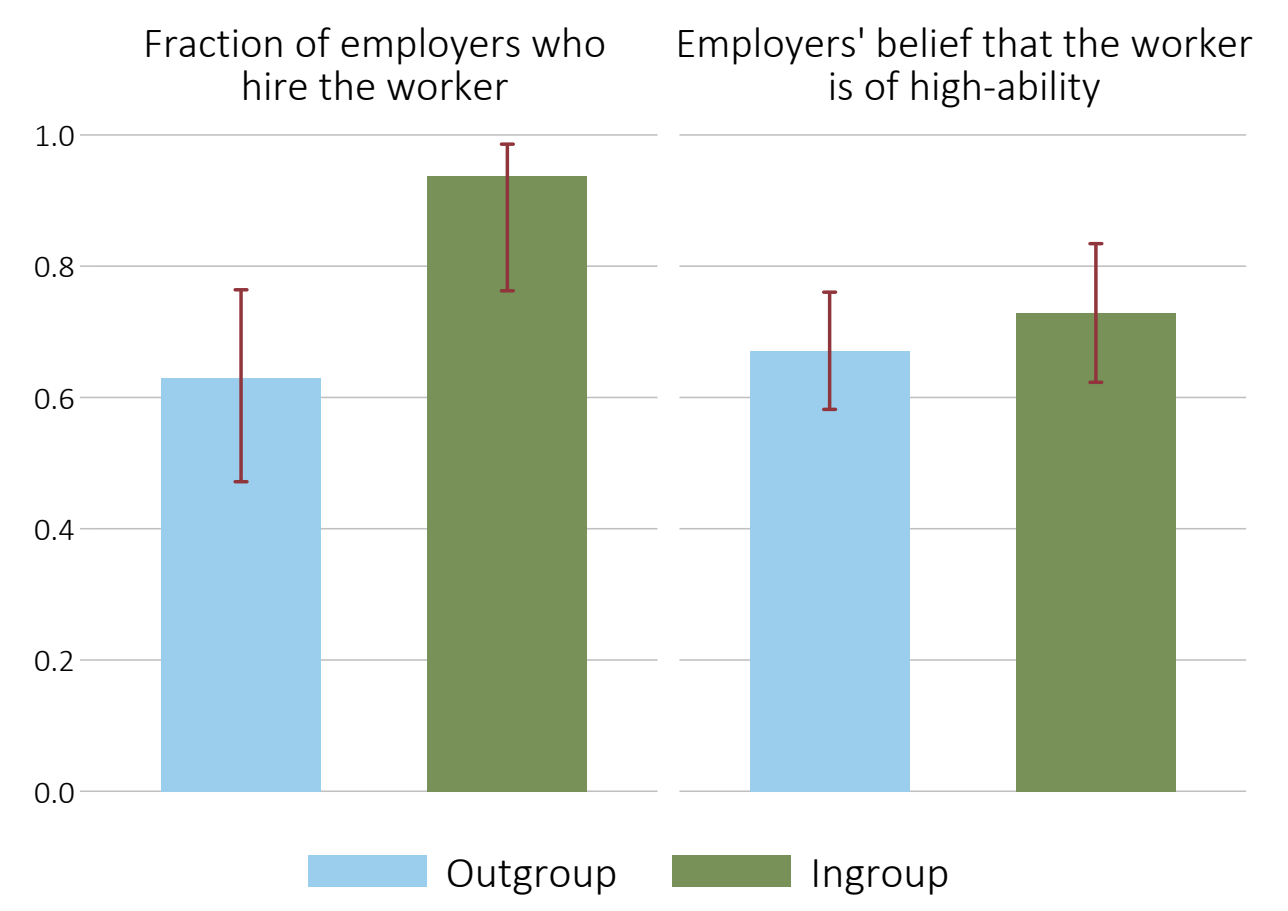

Figure 3. Fraction of employers who hire and their average belief that the worker is of high-ability in Fixed

Note: Only for employers who receive the high-ability message. Error bars depict $90 \%$ confidence intervals. Ingroup and outgroup pairs are determined by the workers' initial identity.

out of 43). Notably, the employers' average belief of being matched with a high-ability worker equals $69.3 \%$, which is very close to the threshold above which hiring is profitable $\left(b_{H}^{*}=70 \%\right)$. It is also close to the observed fraction of high-ability workers among those who send the highability message, namely $67.4 \%$.

Figure 3 depicts the fraction of employers who hire the worker and their mean belief that the worker is of high ability. It shows that $93.7 \%$ of employers who receive the high-ability message hire ingroup workers (15 out of 16 ) but only $62.9 \%$ hire outgroup workers (17 out of 27 ; $\chi^{2}$ test, $p=0.025)$. Hence, we find evidence of discrimination against outgroup workers, supporting Conjecture 2. Interestingly, employers' beliefs of being matched with a high-ability worker are not significantly different between ingroup and outgroup pairs (72.9\% vs. $67.1 \%$; Mann-Whitney $\mathrm{U}$ test, $p=0.574$ ), which suggests that employers' discrimination is not statistical but rather taste-based (see Conjecture 3).

Result 2 With fixed identities, employers are equally likely to believe the message of ingroup and outgroup workers. However, employers are more likely to hire ingroup than outgroup workers, providing evidence for taste-based rather than statistical discrimination.

Next, we look at the Flexible treatment. In this treatment, only $47.7 \%$ of the workers who send the high-ability message are hired (21 out of 44). The fraction of employers who hire is significantly lower in Flexible than in Fixed ( $\chi^{2}$ test, $\left.p=0.011\right)$. In line with the lower hiring 


\section{Fraction of employers who Employers' belief that the worker hire the worker is of high-ability}

1.0

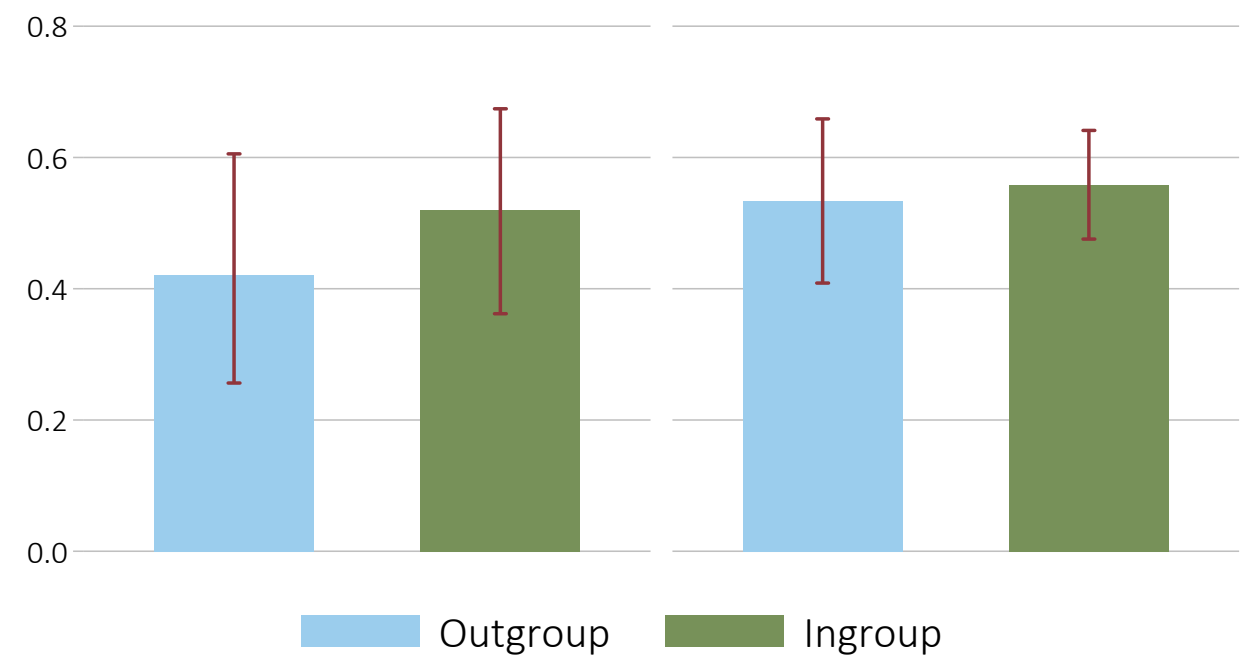

Figure 4. Fraction of employers who hire and their average belief that the worker is of high-ability in Flexible

Note: Only for employers who received the high-ability message. Error bars depict $90 \%$ confidence intervals. Ingroup and outgroup pairs are determined by the workers' initial identity.

rate, the employers' belief of being matched with a high-ability worker is significantly lower in Flexible than in Fixed (54.8\% vs. 69.3\%; Mann-Whitney U test, $p=0.020$ ) and is close to 50\%, the belief one would hold if the high-ability message is uninformative of the worker's ability.

For employers in Flexible who receive the high-ability message, Figure 4 depicts the fraction of them who hire the worker and their mean belief that the worker is of high ability. Workers in ingroup pairs are hired at roughly the same rate as workers in outgroup pairs: $52.0 \%$ for ingroup workers (13 out of 25 ) vs. $42.1 \%$ for outgroup workers ( 8 out of $19 ; \chi^{2}$ test, $p=0.515$ ). Hence, the difference in hiring between Fixed and Flexible is mostly driven by a difference in the fraction of hired ingroup workers. The hiring rate in ingroup pairs is significantly higher in Fixed than in Flexible ( $\chi^{2}$ test, $p=0.005$ ), while there is no significant difference for outgroup pairs ( $\chi^{2}$ test, $p=0.162$ ). As in Fixed, in Flexible, we do not find that the employers' belief about the workers' ability differs significantly between ingroup and outgroup pairs $(55.8 \%$ vs. $53.4 \%$; Mann-Whitney U test, $p=0.595)$. Compared to Fixed, employers in Flexible are more pessimistic of being matched with a high-ability worker in ingroup pairs (72.9\% in Fixed vs. $55.8 \%$ in Flexible; Mann-Whitney U test, $p=0.049)$ and outgroup pairs (67.1\% in Fixed vs. $53.4 \%$ in Flexible; Mann-Whitney U test, $p=0.147)$.

In Table 1 we analyze the employers' hiring decisions controlling for their beliefs. Specifically, we run linear probability regressions with the employers' hiring decision as the dependent variable. As above, we restrict the sample to employers who received the high-ability message. 
Table 1. Determinants of the employers hiring decision

Note: Linear probability regressions. The dependent variable equals 1 if the employer hires the worker and 0 otherwise. Indicator variables for treatment (Fixed or Flexible) $\times$ pair type (ingroup or outgroup), with outgroup pairs in Fixed as the reference category. Controls include the employers' self-reported risk aversion, age, nationality, gender, and field of study. Robust standard errors in parentheses. ${ }^{* * *},{ }^{* *}$, and ${ }^{*}$ indicate statistical significance at $0.01,0.05$, and 0.10 .

\begin{tabular}{lcccccc}
\hline \hline & $\mathrm{I}$ & $\mathrm{II}$ & $\mathrm{III}$ & $\mathrm{IV}$ & $\mathrm{V}$ & $\mathrm{VI}$ \\
\hline Ingroup pairs in Fixed & $0.308^{* * *}$ & $0.276^{* *}$ & $0.301^{* * *}$ & $0.299^{* *}$ & $0.290^{* *}$ & $0.327^{* * *}$ \\
& $(0.114)$ & $(0.106)$ & $(0.105)$ & $(0.130)$ & $(0.122)$ & $(0.118)$ \\
Outgroup pairs in Flexible & -0.209 & -0.133 & -0.130 & -0.194 & -0.126 & -0.124 \\
& $(0.150)$ & $(0.145)$ & $(0.145)$ & $(0.147)$ & $(0.143)$ & $(0.144)$ \\
Ingroup pairs in Flexible & -0.110 & -0.048 & -0.009 & -0.133 & -0.073 & -0.026 \\
& $(0.140)$ & $(0.132)$ & $(0.133)$ & $(0.136)$ & $(0.130)$ & $(0.129)$ \\
Belief of high-ability & & $0.547^{* * *}$ & & & $0.507^{* * *}$ & \\
& & $(0.180)$ & & & $(0.176)$ & \\
Belief of high-ability $\geq 70 \%$ & & & $0.359^{* * *}$ & & & $0.358^{* * *}$ \\
& & & $(0.096)$ & & & $0.096)$ \\
\hline Demographic controls & No & No & No & Yes & Yes & Yes \\
\hline Observations & 87 & 87 & 87 & 87 & 87 & 87 \\
$R^{2}$ & 0.126 & 0.212 & 0.240 & 0.204 & 0.272 & 0.304 \\
\hline \hline
\end{tabular}

In column I, as independent variables, we add indicator variables for the treatment $\times$ pair-type combinations (the reference category being outgroup pairs in Fixed). This regression simply reproduces the results reported above using non-parametric tests-namely, a significantly higher hiring rate by employers in ingroup pairs in Fixed. In columns II and III, we add the employers' belief of being matched with a high-ability worker. In column II, we add beliefs as point predictions, while in column III, we add them as a dummy variable that equals 1 if the employer's belief is equal to or above the threshold above which hiring is profitable (i.e., $b_{H}^{*}=70 \%$ ). In both regressions, the coefficient of beliefs is large and statistically significant, confirming the importance of beliefs in the employers' decision. ${ }^{14}$ Interestingly, the introduction of beliefs has two effects on the coefficients of the indicator variables. First, it reduces the magnitude of coefficients of ingroup and outgroup pairs in Flexible, making these pairs even more similar to outgroup pairs in Fixed. Second, the introduction of beliefs has little effect on the coefficient of ingroup pairs in Fixed. If we interpret this coefficient as the impact of taste-based discrimination, these regressions support the conclusion that employers discriminate based on taste when identities are fixed but not when they are flexible. Columns IV, V, and VI show that these conclusions are robust to controlling for the employers' self-reported tolerance for risk and demographic characteristics (age, gender, Dutch nationality, and economics major).

Result 3 With flexible identities, employers are equally likely to hire and believe the message of ingroup and outgroup workers. Compared to fixed identities, flexible identities reduce the hiring

\footnotetext{
${ }^{14}$ We also ran regressions using a set of dummy variables to divide beliefs into ten equally-spaced categories. The results are qualitatively and quantitatively unchanged in this more-flexible specification.
} 
Table 2. Allocation efficiency and average expected earnings by treatment and pair type

Note: Allocation efficiency is the fraction of pairs in which the employer hires a high-ability worker or does not hire a low-ability worker. Statistics are calculated by simulating all possible pairings considering the employers' hiring rate (conditioning on the message received) and the workers' lying rate (conditioning on their ability). Standard deviations in parenthesis.

\begin{tabular}{lccccc}
\hline \hline \multirow{2}{*}{ Condition } & $\begin{array}{c}\text { Allocation } \\
\text { efficiency }\end{array}$ & \multicolumn{3}{c}{ Expected earnings (in €) } \\
\cline { 3 - 6 } & (in \%) & Overall & Workers & Employers & $\begin{array}{c}\text { Employers } \\
\text { who hire }\end{array}$ \\
\hline Outgroup pairs in Fixed & 61.9 & 7.55 & 8.53 & 6.57 & 6.16 \\
Ingroup pairs in Fixed & $(48.6)$ & $(2.21)$ & $(1.50)$ & $(4.31)$ & $(6.00)$ \\
Outgroup pairs in Flexible & 75.0 & 7.93 & 8.83 & 7.03 & 7.05 \\
& $(43.3)$ & $(2.42)$ & $(1.46)$ & $(4.61)$ & $(5.91)$ \\
Ingroup pairs in Flexible & 62.6 & 7.46 & 7.88 & 7.04 & 7.14 \\
& $(48.4)$ & $(1.75)$ & $(1.37)$ & $(3.20)$ & $(5.89)$ \\
& 62.1 & 7.50 & 8.20 & 6.81 & 6.52 \\
\hline \hline
\end{tabular}

of ingroup members, suggesting that employers no longer discriminate based on taste.

\section{$3.3 \quad$ Efficiency}

Given the differences in the employers' hiring behavior, it is interesting to investigate the efficiency consequences of ingroup favoritism. We consider two measures of efficiency. The players' earnings and allocation efficiency, defined as the fraction of pairs in which the employer's decision is congruent with the worker's ability (i.e., cases where the employer hires a high-ability worker or does not hire a low-ability worker). In order not to be constrained by the specific matching of the experiment, we calculated these statistics by considering the employers' mean hiring rate conditional on the message they receive and the workers' lying rate conditional on their ability and then simulating all possible pairings. Table 2 presents the allocation efficiency and average expected earnings by treatment and by pair type. It also reports the average expected earnings of workers and employers separately.

In all conditions, allocation efficiency and overall earnings are above the no-hiring benchmark obtained with traditional assumptions (i.e., $50 \%$ allocation efficiency and $€ 7$ in earnings). Comparing across conditions, we see that allocation efficiency and earnings are noticeably higher for ingroup pairs in Fixed. This is a direct consequence of there being truthful low-ability workers in all conditions, but a significantly higher hiring rate of workers who send the high-ability message in ingroup pairs in Fixed.

If we look at earnings by role, we see that workers earn considerably more than in the no-hiring benchmark (i.e., $€ 7){ }^{15}$ By contrast, the earnings of employers are close to $€ 7$. Looking at the employers' earnings conditional on hiring (last column in Table 2) shows that

\footnotetext{
${ }^{15}$ Since the workers' earnings depend solely on whether they are hired, their earnings mirror the employers' behavior. Namely, workers who send the high-ability message earn more if they are in an ingroup pair in Fixed.
} 
their expected earnings when they hire are not far from the $€ 7$ they earn if they do not hire, especially in ingroup pairs in Fixed. ${ }^{16}$ This might be an important reason why we observe taste-based discrimination. Namely, discriminating against outgroup workers is not costly.

\section{Conclusion}

We examine the effects of group identity on hiring decisions where employers cannot observe the workers' abilities, but workers can communicate their ability through cheap-talk messages. We ask whether sharing an identity helps workers and employers overcome the adverse selection problem inherent in these decisions and whether the resulting discrimination is statistical or taste-based. We investigate these questions in settings where identities are fixed and flexible.

We find that employers discriminate in favor of ingroup workers when identities are fixed. Notably, employers do not hold differing beliefs about the ability or truthfulness of ingroup and outgroup workers. This leads us to conclude that the observed discrimination is taste-based. In this respect, it is important to note that the workers' truthfulness and the employers' beliefs are such that the average cost of exercising ingroup favoritism is very low, which might be the reason why we observe taste-based discrimination. The literature on identity reports mixed results, from null effects to significant ingroup favoritism (Pechar and Kranton, 2017). The expected cost of discrimination is a plausible explanation for these diverse findings. Another notable result is the effect of group identity on efficiency. Because hiring rates are low due to adverse selection, the increased rate at which employers hire ingroup workers increases overall efficiency. However, since workers are not more honest towards ingroup employers, the benefits of the higher hiring rate are accrued solely by ingroup workers.

Introducing the possibility to change identity reduces the employers' trust in the workers' truthfulness. Workers are equally likely to lie about their ability, but the employers' belief of being matched with a high-ability worker after seeing a high-ability message is noticeably lower, resulting in a lower hiring rate. This is the case even though the actual number of workers changing identity is extremely low. Flexible identities also eliminate the differential hiring rates between ingroup and outgroup pairs. However, it is unclear why. On the one hand, flexible identities might dampen the taste-based component of ingroup favoritism. On the other hand, the change in the employers' beliefs implies that their expected cost of exercising ingroup favoritism is higher than with fixed identities. Further research would be needed to determine the precise reason for the change.

Overall, our findings in this paper suggest that ingroup favoritism can help alleviate adverse

\footnotetext{
${ }^{16}$ Given the previous results, this is an expected finding. The fraction of low-ability workers who lie is close to $\theta^{*} \approx 42.9 \%$ in all conditions (see Figure 2 ). In fact, the fraction of lying low-ability workers is not significantly different from this threshold in any treatment $\times$ pair-type combination (Binomial probability tests, $p>0.489$ ) .
} 
selection problems in hiring decisions. This is another potential explanation for why discrimination in labor markets persists, even if it is taste-based and there is market competition (Becker, 1971). Our findings also suggest that, in hiring decisions where adverse selection is a problem, discrimination ought to be more common for identities that are less flexible, such as gender and race, than for identities that are easier to change or disguise, such as political and regional identities.

\section{References}

Abeler, J., Nosenzo, D., and Raymond, C. (2019). Preferences for Truth-Telling. Econometrica, 87(4):1115-1153.

Akerlof, G. A. and Kranton, R. E. (2000). Economics and Identity. The Quarterly Journal of Economics, 115(3):715-753.

Arai, M. and Thoursie, P. S. (2009). Renouncing Personal Names: An Empirical Examination of Surname Change and Earnings. Journal of Labor Economics, 27(1):127-147.

Becker, G. S. (1971). The Economics of Discrimination. University of Chicago Press, Chicago.

Bénabou, R., Falk, A., and Tirole, J. (2020). Narratives, Imperatives, and Moral Persuasion. Working paper, Princeton University.

Benistant, J. and Villeval, M. C. (2019). Unethical behavior and group identity in contests. Journal of Economic Psychology, 72:128-155.

Bernard, M., Hett, F., and Mechtel, M. (2016). Social identity and social free-riding. European Economic Review, 90:4-17.

Bertrand, M. and Mullainathan, S. (2004). Are Emily and Greg More Employable Than Lakisha and Jamal? A Field Experiment on Labor Market Discrimination. American Economic Review, 94(4):9911013.

Biavaschi, C., Giulietti, C., and Siddique, Z. (2017). The Economic Payoff of Name Americanization. Journal of Labor Economics, 35(4):1089-1116.

Burke, P. J. (2006). Identity Change. Social Psychology Quarterly, 69(1):81-96.

Butler, J. V. (2014). Trust, Truth, Status and Identity: An Experimental Inquiry. The B.E. Journal of Theoretical Economics, 14(1):293-338.

Chandra, K. (2006). What is ethnic identity and does it matter? Annual Review of Political Science, 9(1):397-424.

Charness, G. and Dufwenberg, M. (2011). Participation. American Economic Review, 101(4):1211-1237.

Charness, G., Rigotti, L., and Rustichini, A. (2007). Individual Behavior and Group Membership. American Economic Review, 97(4):1340-1352.

Charness, G. and Shmidov, V. (2014). Trust and Reciprocity. Foundations and Trends@ in Microeconomics, 10(3):167-207.

Chen, R. and Chen, Y. (2011). The Potential of Social Identity for Equilibrium Selection. American Economic Review, 101(6):2562-2589.

Chen, Y. and Li, S. X. (2009). Group Identity and Social Preferences. American Economic Review, 
$99(1): 431-457$.

Dickinson, D. L., Masclet, D., and Peterle, E. (2018). Discrimination as favoritism: The private benefits and social costs of in-group favoritism in an experimental labor market. European Economic Review, 104:220-236.

Eckel, C. C. and Grossman, P. J. (2005). Managing diversity by creating team identity. Journal of Economic Behavior \& Organization, 58(3):371-392.

Edo, A., Jacquemet, N., and Yannelis, C. (2019). Language skills and homophilous hiring discrimination: Evidence from gender and racially differentiated applications. Review of Economics of the Household, $17(1): 349-376$.

Falk, A. and Zehnder, C. (2013). A city-wide experiment on trust discrimination. Journal of Public Economics, 100:15-27.

Feldhaus, C. and Mans, J. (2014). Who do you lie to? Social identity and the cost of lying. Working Paper Series in Economics 76, University of Cologne.

Gioia, F. (2017). Peer effects on risk behaviour: the importance of group identity. Experimental Economics, 20(1):100-129.

Hargreaves Heap, S. P. and Zizzo, D. J. (2009). The Value of Groups. American Economic Review, 99(1):295-323.

Hett, F., Kröll, M., and Mechtel, M. (2017). Choosing Who You Are: The Structure and Behavioral Effects of Revealed Identification Preferences. Annual Conference German Economic Association.

Karni, E. (2009). A Mechanism for Eliciting Probabilities. Econometrica, 77(2):603-606.

Kranton, R. E. and Sanders, S. G. (2017). Groupy versus Non-Groupy Social Preferences: Personality, Region, and Political Party. American Economic Review Papers and Proceedings, 107(5):65-69.

Maximiano, S. and Chakravarty, S. (2016). Deception, Social Preferences, and Friendship. SSRN Working Paper 3589537.

Oreopoulos, P. (2011). Why Do Skilled Immigrants Struggle in the Labor Market? A Field Experiment with Thirteen Thousand Resumes. American Economic Journal: Economic Policy, 3(4):148-171.

Pechar, E. and Kranton, R. (2017). Moderators of Intergroup Discrimination in the Minimal Group Paradigm: A MetaAnalysis. Working paper, Duke University.

Rakić, T., Steffens, M. C., and Mummendey, A. (2011). When it matters how you pronounce it: The influence of regional accents on job interview outcome. British Journal of Psychology, 102(4):868-883.

Riach, P. A. and Rich, J. (2002). Field Experiments of Discrimination in the Market Place. The Economic Journal, 112(483):F480-F518.

Rivera, L. A. (2012). Hiring as Cultural Matching. American Sociological Review, 77(6):999-1022.

Robin, S., Rusinowska, A., and Villeval, M. C. (2014). Ingratiation: Experimental evidence. European Economic Review, 66:16-38.

Rong, R., Houser, D., and Dai, A. Y. (2016). Money or friends: Social identity and deception in networks. European Economic Review, 90:56-66.

Shayo, M. (2009). A Model of Social Identity with an Application to Political Economy: Nation, Class, and Redistribution. American Political Science Review, 103(2):147-174.

Tajfel, H. (1970). Experiments in Intergroup Discrimination. Scientific American, 223(5):96-103. 


\section{Appendix A Sample of screenshots from the Flexible treatment}

Welcome and thank you for participating in this study!

\section{General Instructions}

You are going to participate in a study on economic decision making and will be asked to make a number of decisions. For your participation you will receive a show-up fee of $5 €$. Please read these instructions carefully as they describe how you can earn additional money

All the interaction between you and other participants will take place through the computers. Please do not talk or communicate in any other way with other

participants. The use of mobile phones is strictly forbidden. If you have a question, please raise your hand and one of us will come to you and answer your question in private.

Important: If you are found violating these rules, you will both forfeit any earnings from this experiment and may be excluded from future experiments.

This study is anonymous: that is, your identity will not be revealed to others and the identity of others will not be revealed to you.

All participants will complete two Parts. You will receive the corresponding instructions at the beginning of each part.

During the study your earnings will be expressed in Euro. Your total earnings will equal the $5 €$ show-up fee plus the earnings from Part 2 . You will be paid your total earnings in cash and in private at the end of the experiment. 


\section{Part 1 - Instructions}

In Part 1, you are asked to indicate which of two smartphones you prefer.

Your answer will remain anonymous.

At the end of each experimental session, every participant will receive a lottery ticket with a number between 1 and 750

On December 1st, we will randomly draw a number between 1 and 750 and inform all participants via email A week before the lottery, we will announce by email the room and the time where the lottery will take place. You are welcome to attend the lottery.

The participant whose number matches the randomly drawn number will receive the smartphone he/she indicated as the preferred one.

Please, answer the question with sincerity.

\section{Indicate your preferences}

Please answer the question below and press the button "Submit".

Which smartphone do you prefer?
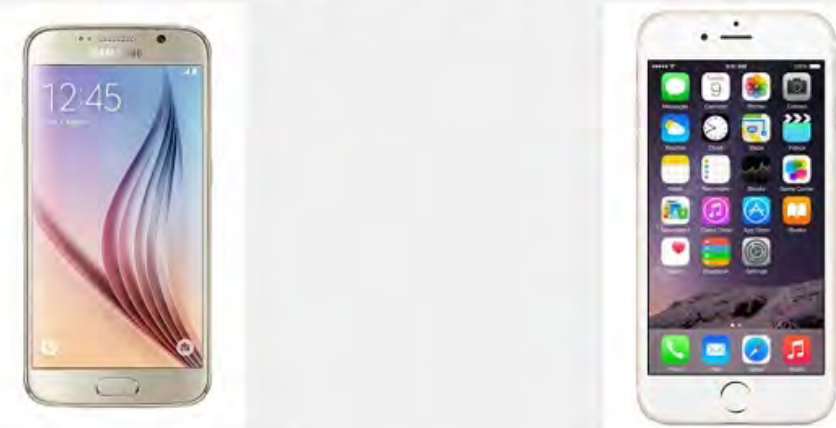

Samsung Galaxy S6 (64GB)

iPhone 6 (64GB)

Please choose one of the two smartphones.

Both smartphones have similar features (weight, size and screen size).

The market value of either phone is around $750 €$

Remember that there will be a lottery for your chosen smartphone at the end of this study. If you win the lottery, you can choose the color of the phone. 


\section{Indicate your preferences}

Please answer the question below and press the button "Submit"

\section{Which smartphone do you prefer?}
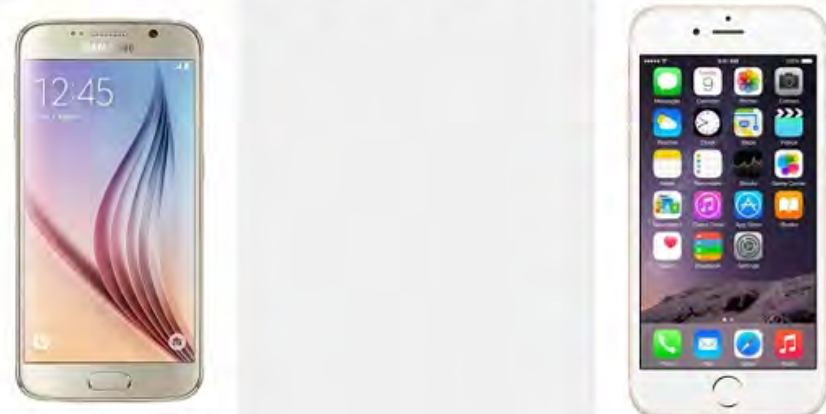

Samsung Galaxy S6 (64GB)

iPhone 6 (64GB)

Please choose one of the two smartphones.

Both smartphones have similar features (weight, size and screen size).

The market value of either phone is around $750 €$

Remember that there will be a lottery for your chosen smartphone at the end of this study. If you win the lottery, you can choose the color of the phone.

\section{Indicate your preferences}

Please answer the question below and press the button "Submit"

How much do you like your chosen smartphone relative to the other one?
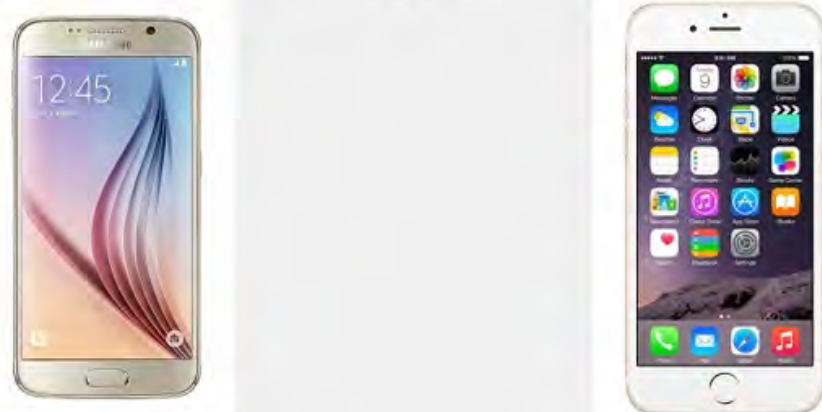

Absolutely Samsung Galaxy S6 $\sim \sim \sim \sim \sim \sim \bullet \sim \sim$ Absolutely iPhone 6

Click on "Submit" to proceed to the next screen. 


\section{Part 2: General instructions}

In Part 2, all participants will be randomly assigned to one of two possible roles. Half of the participants will be assigned the role of Player A and the other half the role of Player B.

Each Player A will be randomly paired with one Player B. Since this study is anonymous, no participant will ever know the identity of the person he/she is paired with.

Part 2 will consist of two stages: Stage 1 and Stage 2. At the end of the experiment, one Stage will be randomly drawn and everyone in the session will be paid according to the decisions in that stage.

Click on "Next" once you are done reading these instructions.

\section{Role information}

You have been assigned the role of Player B

You will keep this role during the entire study

Click on "Next" once you are done reading the information. 
Part 2 - Stage 1 - Instructions

All Player Bs have been randomly assigned by the computer to one of two groups: to the HIGH group or to the LOW group. Half the Player Bs in the room are assigned to the HIGH group and the other half to the LOW group. In other words, the probability that your paired Player B is HIGH equals $50 \%$

Earnings in this stage depend on the decisions made in your pair and, in some cases, on a six-sided die that will be thrown by Player $\mathrm{B}$ at the end of this session.

First, Player A chooses between LEFT and RIGHT. Then, Player B is informed of Player A's choice and chooses between ACCEPT and REJECT. Earnings in this stage will be determined by the table on the right. Note that

- If Player A chooses LEFT and Player B chooses REJECT, then both receive $5 €$

- If Player A chooses LEFT and Player B chooses ACCEPT, then both receive $7 €$

- If Player A chooses RIGHT and Player B chooses REJECT,

then both receive $5 €$

- If Player A chooses RIGHT and Player B chooses ACCEPT then Player $B$ receives $10 €$ and throws a die at the end of the experiment. The earnings of Player A depend on Player $B$ 's group (HIGH or LOW) and on the die throw.

- If Player B is LOW, then Player A receives $0 €$

- If Player $B$ is $\mathrm{HIGH}$, then Player A receives $0 €$ if the outcome of the die throw is number 1 and $12 €$ if it is numbers 2 through 6 .

Player A will not observe the die throw. Thus, if Player A earns $0 €$, he/she cannot tell whether Player B is HIGH or LOW

\begin{tabular}{|c|c|c|c|c|}
\hline $\begin{array}{c}\text { A's } \\
\text { choice } \\
\begin{array}{c}\text { B's } \\
\text { choice }\end{array}\end{array}$ & REJECT & ACCEPT & REJECT & ACCEPT \\
\hline $\begin{array}{c}\text { A's } \\
\text { earnings }\end{array}$ & $5 €$ & $7 €$ & $5 €$ & $\begin{array}{c}\text { RIGHT } \\
\begin{array}{c}\text { B is HIGH } \\
2 € \text { if die }=2-6 \\
0 € \text { if die }=1 \\
\text { B is Low } \\
0 €\end{array}\end{array}$ \\
\hline $\begin{array}{c}\text { B's } \\
\text { earnings }\end{array}$ & $5 €$ & $7 €$ & $5 €$ & $10 €$ \\
\hline
\end{tabular}

To summarize

Player B always earns more money if Player A chooses RIGHT.

- If Player B chooses ACCEPT, on average, Player A earns more money by choosing RIGHT only if Player $B$ is in the HIGH group

- The difficulty for Player $\mathrm{A}$ is that he/she does not know whether

Player $B$ is from the HIGH or LOW group.

\section{Part 2 - Stage 1 - Instructions}

\section{Messaging}

Before Player A and Player B make their choice, Player B has the opportunity to send a one-way message to Player A Player B can choose one of two pre-formulated messages about the group he/she has been assigned to; that is, player B can send either one of the following messages: "I am in the LOW group' or 'I am in the HIGH group'.

Player A will receive the message before he/she makes his/her choice

\section{Revising selection of smartphone}

Before Player B sends a message to Player A, Player B will see Player A's chosen smartphone and have the opportunity to change his/her selected smartphone. If Player B decides to revise his/her choice, this implies that he/she will participate in a lottery for the newly chosen smartphone. Player A will only see Player B's finally chosen smartphone before he/she makes his/her choice. Player A will not know whether Player B revised his/her choice or not

\section{Information on the next screen}

Player B will learn whether he/she is in the HIGH or the LOW group. Moreover, Player B will learn which smartphone Player A selected in Part 1.

Player A will not learn whether Player B is in the HIGH or the LOW group. However, Player A will learn the finally selected smartphone by Player B, but will not know whether Player B revised his/her choice or not

\begin{tabular}{|c|c|c|c|c|}
\hline $\begin{array}{c}\text { A's } \\
\text { choice } \\
\text { B's } \\
\text { choice }\end{array}$ & $\begin{array}{c}\text { LEFT } \\
\text { REJECT }\end{array}$ & $\begin{array}{c}\text { LEFT } \\
\text { ACCEPT }\end{array}$ & $\begin{array}{l}\text { RIGHT } \\
\text { REJECT }\end{array}$ & $\begin{array}{c}\text { RIGHT } \\
\text { ACCEPT }\end{array}$ \\
\hline $\begin{array}{c}\text { A's } \\
\text { earnings }\end{array}$ & $5 €$ & $7 €$ & $5 €$ & $\begin{array}{c}\text { B is HIGH } \\
12 € \text { if die }=2 \cdot 6 \\
0 € \text { if die=1 } \\
B \text { is LoW } \\
0 €\end{array}$ \\
\hline $\begin{array}{c}\text { B's } \\
\text { earnings }\end{array}$ & $5 €$ & $7 €$ & $5 €$ & $10 €$ \\
\hline
\end{tabular}

\section{Comprehension questions}

Please answer the following questions to confirm your understanding of the instructions.

1. If Player A chooses LEFT and Player B chooses ACCEPT, what are the earnings of:

a) Player $A$ if Player $B$ is HIGH?

b) Player A if Player B is LOW?

c) Player $B$ if he/she is HIGH?

d) Player B if he/she is LOW?

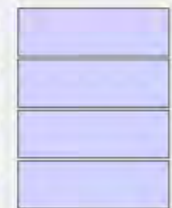




\section{Part 2 - Stage 1}

Player A with whom you are paired chose the Samsung Galaxy S6.

Previously, you chose the iPhone 6

\section{Do you want to change to the Samsung Galaxy $\mathbf{S 6}$ instead?}

Please answer the question and press the button "Submit".

$\checkmark$ No, I want to keep the iPhone 6

$\ulcorner$ Yes, I want to change to the Samsung Galaxy S6

You can now send a message to Player $A$.

Please, select below the message you wish to send. The message will be transmitted to Player A. Note that Player A cannot reply to your message.

Message

$\checkmark \mathrm{I}$ am in the LOW group

- lam in the HIGH group

\section{Part 2 - Stage 1 - Message}

\begin{tabular}{c|c|c|c|c|}
$\begin{array}{c}\text { A's } \\
\text { choice }\end{array}$ & LEFT & LEFT & RIGHT & RIGHT \\
$\begin{array}{c}\text { B's } \\
\text { choice }\end{array}$ & REJECT & ACCEPT & REJECT & ACCEPT \\
\hline $\begin{array}{c}\text { A's } \\
\text { earnings }\end{array}$ & $5 €$ & $7 €$ & $5 €$ & $\begin{array}{c}\text { B is HIGH } \\
12 € \text { if die=2-6 } \\
0 € \text { if die=1 } \\
\text { B is LOW } \\
0 €\end{array}$ \\
\hline $\begin{array}{c}\text { B's } \\
\text { earnings }\end{array}$ & $5 €$ & $7 €$ & $5 €$ & $10 €$ \\
\hline
\end{tabular}

Remember that:

- You always earn more money if Player A chooses RIGHT

- Your group affects Player A's earnings if he/she chooses RIGHT - The difficulty for Player A is that he/she does not know whether you are in the HIGH or in the LOW group. However, you can send a text message to Player A

\section{Information}

You are Player B and you are in the LOW group.

You chose the Samsung Galaxy S6 edge.

Player A chose the iPhone 6 


\section{Part 2 - Stage 1 - Your choice}

\section{Information}

Player B knows whether he/she is in the HIGH or the LOW group.

You chose the iPhone 6

Player B chose the Samsung Galaxy S6 edge

\begin{tabular}{|c|c|c|c|c|}
\hline $\begin{array}{c}\text { A's } \\
\text { choice } \\
\text { B's } \\
\text { choice }\end{array}$ & $\begin{array}{c}\text { LEFT } \\
\text { REJECT }\end{array}$ & $\begin{array}{c}\text { LEFT } \\
\text { ACCEPT }\end{array}$ & $\begin{array}{l}\text { RIGHT } \\
\text { REJECT }\end{array}$ & $\begin{array}{c}\text { RIGHT } \\
\text { ACCEPT }\end{array}$ \\
\hline $\begin{array}{c}\text { A's } \\
\text { earnings }\end{array}$ & $5 €$ & $7 €$ & $5 €$ & $\begin{array}{c}\text { B is HIGH } \\
12 € \text { if die=2-6 } \\
0 € \text { if die }=1 \\
B \text { is LoW } \\
0 €\end{array}$ \\
\hline $\begin{array}{c}\text { B's } \\
\text { earnings }\end{array}$ & $5 €$ & $7 €$ & $5 €$ & $10 €$ \\
\hline
\end{tabular}

You are Player A

Please make your choice $\subset$ LEFT

S RIGHT

Part 2 - Stage 1 - Your choice

Information

You are Player B and you are in the LOW group You chose the Samsung Galaxy S6 edge

Player A chose the iPhone 6

\section{Player A chose RIGHT}

\begin{tabular}{|c|c|c|c|c|}
\hline $\begin{array}{c}\text { A's } \\
\text { choice }\end{array}$ & LEFT & LEFT & RIGHT & RIGHT \\
\hline $\begin{array}{c}\text { B's } \\
\text { choice }\end{array}$ & REJECT & ACCEPT & REJECT & ACCEPT \\
\hline $\begin{array}{c}\text { A's } \\
\text { earnings }\end{array}$ & $5 €$ & $7 €$ & $5 €$ & $\begin{array}{c}\text { B is HIGH } \\
12 € \text { if die }=2-6 \\
0 \in \text { if die }=1 \\
B \text { is LoW } \\
0 \in\end{array}$ \\
\hline $\begin{array}{c}\text { B's } \\
\text { earnings }\end{array}$ & $5 €$ & $7 €$ & $5 €$ & $10 €$ \\
\hline
\end{tabular}

Please make your choice $\because$ ACCEPT

REJECT 


\section{Part 2 - Stage 2 - Instructions}

You will complete 2 - Stage 2 while you wait for Player B. In this part, we will ask you to answer the following question:

What is the probability that Player B is in the LOW group?

For example, if you think there is a $10 \%$ chance that Player B is in the HIGH group and a $90 \%$ chance that Player B is in the

LOW group, then enter 90 as your probability that Player B is in the LOW group

If Part 2 - Stage 2 is selected for payment, you will earn money depending on the accuracy of your prediction. Specifically we will compare the actual group of Player B to your prediction and pay you according to a procedure designed by Prof. Edi Karni to reward accurate predictions. According to this procedure, you maximize your expected earnings when your submitted prediction equals your actual belief that Player B is in the LOW group. The details of the procedure are not crucial as long as you are aware that submitting a prediction that is not your actual belief will decrease your expected earnings and will not reduce your risk (variation in earnings). The mathematical prof is complex, but if you wish earnings). The mathematicalproof is compl icle at the end of the study. The procedure is described by the figure.
You submit a prediction $(P)$ of the chance that Player $B$ is LOW (between 0 and 100)

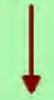

At the end of the study, you will throw two ten-sided dice to get a random number (RN) between 0 and 99

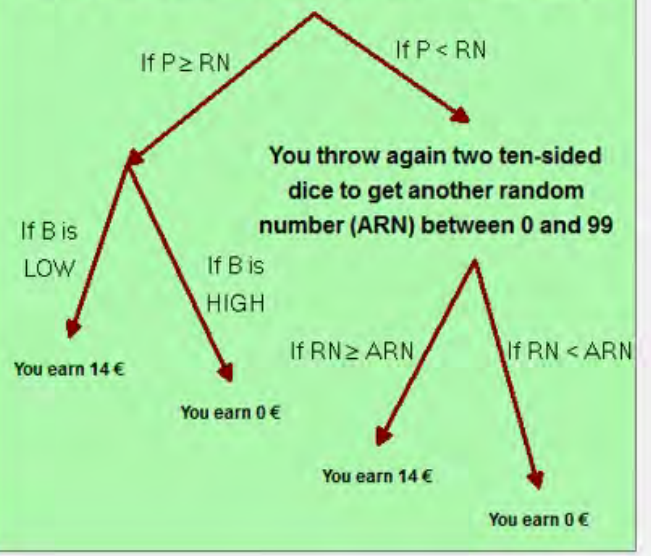

\section{Predict the other's group - Instructions}

Test question

Please answer the following question to confirm your understanding of the instructions.

If you think that there is a $60 \%$ chance that Player B is in the LOW group, what is the prediction that maximizes your expected earnings in Part 2 - Stage 2?
$\checkmark \%$ probability that Player B is LOW
$\sim 25 \%$ probability that Player B is LOW
ᄃ $40 \%$ probability that Player B is LOW
- $60 \%$ probability that Player B is LOW
ᄃ $90 \%$ probability that Player B is LOW 
Part 2 - Stage 2 - Your prediction

Information

Player B knows whether he/she is in the HIGH or in the LOW group. The only information you have is provided below.

Player B selected the Samsung Galaxy S6 edge.

Below is the message sent by Player $B$.

I am in the HIGH group.

\begin{tabular}{|c|c|c|c|c|}
\hline $\begin{array}{c}\text { A's } \\
\text { choice } \\
\text { B's } \\
\text { choice }\end{array}$ & $\begin{array}{c}\text { LEFT } \\
\text { REJECT }\end{array}$ & $\begin{array}{c}\text { LEFT } \\
\text { ACCEPT }\end{array}$ & $\begin{array}{l}\text { RIGHT } \\
\text { REJECT }\end{array}$ & $\begin{array}{l}\text { RIGHT } \\
\text { ACCEPT }\end{array}$ \\
\hline $\begin{array}{c}\text { A's } \\
\text { earnings }\end{array}$ & $5 €$ & $7 €$ & $5 €$ & $\begin{array}{c}\text { B is HIGH } \\
12 € \text { if die=2-6 } \\
0 € \text { if die }=1 \\
B \text { is LoW } \\
0 €\end{array}$ \\
\hline $\begin{array}{c}\text { B's } \\
\text { earnings }\end{array}$ & $5 €$ & $7 €$ & $5 €$ & $10 €$ \\
\hline
\end{tabular}

What is the probability that Player B is in the LOW group? (Type in a whole number between 0 and 100 )

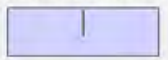

Remember, you earn money depending on the accuracy of your prediction and you maximize your expected earnings by submitting your actual belief that Player $B$ is in the LOW group. To read again the description of the procedure, click on "Procedure"

\section{Part 2 - Stage 2 - Instructions}

In this stage, Player A will answer the following question:

\section{What is the probability that Player B is in the LOW group?}

For example, if Player A thinks there is a $10 \%$ chance that you are in the HIGH group and a $90 \%$ chance that you are in the LOW group, then he/she will answer 90 as your probability that you are in the LOW group.

Your task in this stage is to guess Player A's answer to the above question. If Part 2 - Stage 2 is selected for payment, you will earn money depending on the accuracy of your guess. Specifically, you enter your guess by selecting checkboxes like the ones in the picture to the right. We will compare the actual answer of Player A to your guess and pay you in the following way. If Player A's answer falls in one of the ranges you selected then you earn a positive amount.

Importantly, the more ranges you select, the lower your earnings if you are correct (see the table below). If Player A's answer falls outside your selected ranges then you earn $0 €$

\begin{tabular}{|c|c|c|}
\hline $\begin{array}{c}\text { \# of checked } \\
\text { ranges }\end{array}$ & Earnings if correct & Earnings if wrong \\
\hline 1 & 14 & 0 \\
\hline 2 & 11 & 0 \\
\hline 3 & 8 & 0 \\
\hline 4 & 5 & 0 \\
\hline 5 & 2 & 0 \\
\hline 6 or more & 0 & 0 \\
\hline
\end{tabular}

Player A will answer the following question:

What is the probability that Player B is in the LOW group?

In which range (or ranges) will Player A's answer fall?

$$
\begin{aligned}
& \ulcorner 0 \text { to } 4 \\
& \ulcorner 5 \text { to } 14 \\
& \ulcorner 15 \text { to } 24 \\
& \ulcorner 25 \text { to } 34 \\
& \Gamma 35 \text { to } 44 \\
& \ulcorner 45 \text { to } 54 \\
& \Gamma 55 \text { to } 64 \\
& \Gamma 65 \text { to } 74 \\
& \ulcorner 75 \text { to } 84 \\
& \ulcorner 85 \text { to } 94 \\
& \ulcorner 95 \text { to } 100
\end{aligned}
$$

Your earnings if you are correct: $14 €$

Your earnings if you are wrong: 


\section{Part 2 - Stage 2 - Your prediction}

\section{Information}

The only information Player A had when answering his/her question is provided below.

Player B selected the Samsung Galaxy $\$ 6$ edge

Below is the message sent by Player $B$.

I am in the HIGH group.
Player A will answer the following question:

What is the probability that Player B is in the LOW group?

In which range (or ranges) will Player A's answer fall?

$$
\begin{aligned}
& \Gamma 0 \text { to } 4 \\
& \Gamma 5 \text { to } 14 \\
& \Gamma 15 \text { to } 24 \\
& \Gamma 25 \text { to } 34 \\
& \Gamma 35 \text { to } 44 \\
& \text { 『 } 45 \text { to } 54 \\
& \nabla 55 \text { to } 64 \\
& \Gamma 65 \text { to } 74 \\
& \Gamma 75 \text { to } 84 \\
& \Gamma 85 \text { to } 94 \\
& \Gamma 95 \text { to } 100
\end{aligned}
$$

\section{Questionnaire}

Please click "Continue" once you are done answering the questions

Generally speaking, are you a person who is ready to take risks or are you trying to avoid risks?

Unwilling to take risks $c \sim \sim \sim \sim \sim \sim \sim \sim \sim \sim$ Fully prepared to take risks

What is your age?

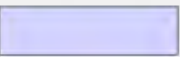

What is your gender? $\subset$ Female

$\checkmark$ Male

From which country do you come from?

$\ulcorner$ Netherlands

$c$ Germany

$\checkmark$ Rest of Europe

$\checkmark$ Africa

America

r Asia

r Australia
You are currently a student of:

c Maastricht University

$\checkmark$ University College Maastricht

r Tilburg University

$\checkmark$ Other university

r Not a student

What is your field of studies?

$\sim$ Natural Sciences

$\sim$ Economics/Business/Finance

$\checkmark$ Engineering

$\checkmark$ Humanities

$\checkmark$ Psychology

c Social Sciences

$\checkmark$ Other 
The experiment has ended. Thank you for participating!

We will now throw a six-sided die to determine whether you will be paid according to Stage 1 or Stage 2

The correspondence between parts and numbers is as follows:

Die outcome is 1-3: Part 2 - Stage 1

Die outcome is 4-6: Part 2 - Stage 2.

The part to be paid is Part 2 - Stage 1 - Game

Game outcome:
You chose:
RIGHT
Player B chose:

Therefore Player B will throw a six-sided die.

If Player B's group is HIGH and the outcome of the die throw is numbers 2 through 6 ,

you will earn $12 €$ (plus the $5 €$ show-up fee).

Otherwise, you will earn $0 €$ (plus the $5 €$ show-up fee) 